\title{
Lipid metabolism and accumulation in oilseed crops $^{\text {th }}$
}

\author{
Magdalena Miklaszewska ${ }^{1,2} \mathbb{D}$, Krzysztof Zienkiewicz $^{3}$ D, Pattarapong Inchana $^{3}$ \\ and Agnieszka Zienkiewicz ${ }^{3, *}$ (D) \\ 1 Department of Plant Physiology and Biotechnology, University of Gdańsk, Wita Stwosza 59, 80-308 Gdańsk, Poland \\ 2 Department of Functional and Evolutionary Ecology, Division of Molecular Systems Biology (MOSYS), Faculty of Life Sciences, \\ University of Vienna, Djerassiplatz 1, 1030 Vienna, Austria \\ ${ }^{3}$ Centre for Modern Interdisciplinary Technologies, Nicolaus Copernicus University in Toruń, Wileńska 4, 87-100 Toruń, Poland
}

Received 2 October 2021 - Accepted 22 October 2021

\begin{abstract}
Triacylglycerols (TAGs) serve as the most important storage form of energy and carbon in eukaryotic cells and thus are one of the fundamental macronutrients for animal and human diet. They are also used as a major feedstock for diverse industrial and energetic sectors due to their high energy density. Oilseed crops represent the most valuable source of TAGs and major world sources of edible oils. Originally, oilseeds of various species were used as a model to decipher plant lipid synthesis pathways. Given the continuous progress in research on plant lipid metabolism, here we provide an overview and update on the current state of knowledge related mainly to storage lipids in oilseeds. Moreover, we present the latest evidences on the molecular networks governing metabolism not only of TAGs but also of other seed lipids, like wax esters, sterols and sphingolipids. Finally, this review also provides a framework for understanding the complex lipid web existing in oilseeds.
\end{abstract}

Keywords: fatty acids / lipid droplets / lipid synthesis / oilseeds / triacylglycerols

Résumé - Métabolisme et accumulation de lipides dans les cultures oléagineuses. Les triglycérides (TG) représentent la forme de stockage d'énergie et de carbone la plus importante dans les cellules eucaryotes et donc l'un des macronutriments fondamentaux pour l'alimentation animale et humaine. Ils sont également utilisés comme matière première majeure dans divers secteurs industriels et énergétiques en raison de leur haute densité énergétique. Les oléagineux représentent la source la plus précieuse de TG et les principales sources mondiales d'huiles alimentaires. À l'origine, les oléagineux de diverses espèces ont été utilisés comme modèles pour déchiffrer les voies de synthèse des lipides végétaux. Étant donné les progrès continus de la recherche sur le métabolisme des lipides végétaux, nous fournissons ici une vue d'ensemble et une mise à jour de l'état actuel des connaissances liées principalement aux lipides de stockage dans les graines oléagineuses. Nous présentons aussi les dernières découvertes sur les réseaux moléculaires régissant le métabolisme non seulement des TAG mais aussi d'autres lipides des graines, comme les cires, les stérols et les sphingolipides. Finalement cette revue fournit également un cadre pour la compréhension du réseau lipidique complexe existant dans les graines oléagineuses.

Mots clés : acides gras / gouttelettes lipidiques / synthèse des lipides / oléagineux / triglycérides

\section{Introduction}

Oilseeds are a major global commodity as they contribute significantly to human and livestock nutrition and serve as a major feedstock for diverse branches of chemical industry as

\footnotetext{
Contribution to the Topical Issue "Green and white biotechnologies in the fields of lipids and oil- and proteincrops / Biotechnologies vertes et blanches dans les domaines des lipides et oléoprotéagineux". *Correspondence: agazet@umk.pl
}

well as an important source of renewable energy in the form of biodiesel (Durrett et al., 2008; Dyer et al., 2008). World production of oilseeds has increased dramatically in the last decade and in 2021 it is estimated to reach nearly 600 million metric tons (https://usda.library.cornell.edu). Soybeans (Glycine max) are currently the leading type of oilseeds in the world, followed by rapeseed (Brassica napus), sunflower (Helianthus annuus) and peanuts (Arachis hypogaea), although palm (Elaeis spp.) oil is the world's leading vegetable oil. 

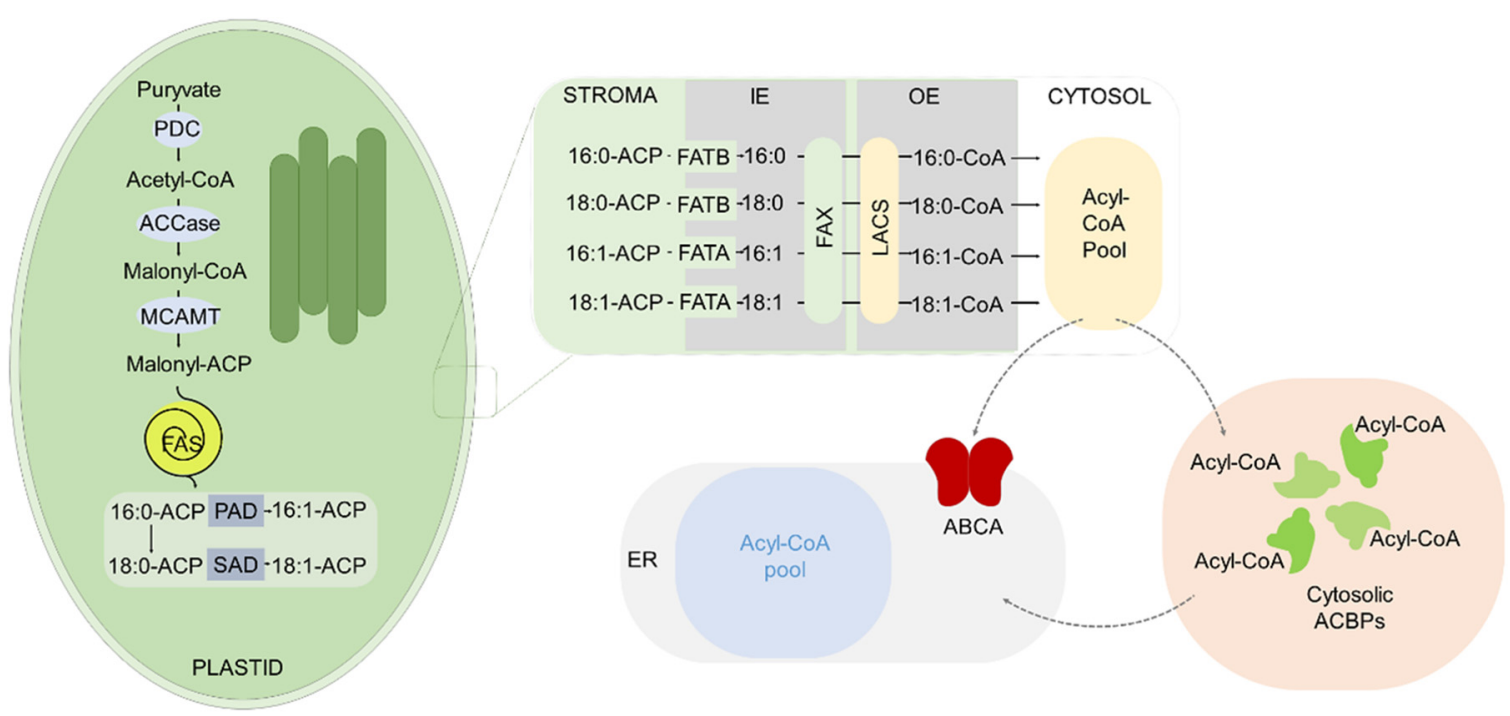

Fig. 1. General overview of fatty acid biosynthesis and eukaryotic pathway of CoAs origin in oilseed cells. Fatty acid synthesis takes place in plastids where malonyl-ACP is used as a substrate. FAs are synthesized by FAS complex in a series of condensation and elongation reactions which lead to formation of FA conjugates with ACP proteins. Their channeling to cytosol includes hydrolysis by thioesterases (FAT) to free fatty acids at the inner plastid envelope membrane (IE), followed by their transfer through the membrane mediated by FAX proteins. Once they reach the outer plastid envelope membrane (OE) they undergo vectorial acylation catalyzed by LACS enzymes. The resulting acyl-CoAs are transferred to the cytosol. The cytosolic pool of acyl-CoAs directly interacts with ACBP proteins, which serve as major transporters of acylCoAs from the cytosol to the ER. In the ER, acyl-CoAs are used as acyl donors for TAGs synthesis pathways. Abbreviations: ABCA: ATPbinding cassette $(\mathrm{ABC})$ transporter subfamily A; ACBPs: acyl-CoA binding proteins; ACCase: acetyl-CoA carboxylase; ACP: acyl carrier protein; CoA: coenzyme A; FAs: fatty acids; FAS: fatty acid synthase complex; FATA/B: fatty acyl-ACP thioesterase; ER: endopsamic reticulum; FAX: fatty acid export protein; IE: inner plastid envelope; LACS: long chain acyl-CoA synthases; MCAMT: malonyl-CoA: acyl carrier protein S-malonyltransferase; OE: outer plastid envelope; PAD: palmitoyl-ACP desaturase; PDC: pyruvate dehydrogenase complex; SAD: stearoyl-ACP desaturase.

The most valuable components of oilseeds are triacylglycerols (TAGs), which are synthesized during seed development and reach the maximum content at seed maturity (Lung and Weselake, 2006). The process of seed formation in oil storing crops, like in all Angiosperms, starts from a successful pollination and fertilization. When a compatible pollen grain lands on the receptive stigma, it germinates into a pollen tube, which usually delivers two sperm cells into the female gametophyte-the embryo sac. During so called double fertilization, one of the sperm cells fuses with the egg cell to form the zygote, whereas the other sperm cell undergoes a fusion with the diploid polar nuclei and gives origin to a triploid endosperm. The zygote, after multiple mitotic divisions, transforms into the embryo, whereas endosperm serves as nutritive tissue for the developing embryo. In turn, the most external layers of the ovule, termed integuments, give rise to the seed coat (Bleckmann et al., 2014; Dresselhaus et al., 2016). The process of seed development is accompanied by a massive accumulation of reserve components, which will serve as energy and carbon sources during seed germination and post-germinative growth of the seedling. The major storage reserves are seed storage proteins (SSPs), carbohydrates (starch), and/or storage lipids (Baud et al., 2008). The latter ones are the major storage reserves in oil crops and are represented mostly by TAGs (Voelker and Kinney, 2001). As this review focuses on lipid metabolism and accumulation in oilseeds, in further sections we characterize the key mechanisms related to these compounds during seed development.
This includes both storage and non-storage lipids in diverse species, with a special emphasis on Arabidopsis thaliana being not only a leading model organism in plant biology and genetics but also a reference model for oil crops.

\section{Everything starts in the plastid}

In seeds and other plant tissues, de novo fatty acid (FA) biosynthesis takes place in plastids (Fig. 1). This biochemical pathway provides acyl chains necessary for the formation of diverse acyl lipids involved in the membrane synthesis or carbon and energy storage. De novo FA synthesis is catalyzed by the type II FA synthase and involves several enzymes and enzymatic complexes including the pyruvate dehydrogenase complex (PDC), acetyl-Co-A carboxylase (ACCase) or fatty acid synthase complex (FAS) (Troncoso-Ponce et al., 2016b). The first committed step of FA synthesis involves formation of malonyl-CoA from acetyl-CoA and bicarbonate by ACCase. Assembly of FAs requires production of malonyl-ACP by transferring malonyl group from $\mathrm{CoA}$ to acyl carrier protein (ACP) catalyzed by a malonyl-CoA: acyl carrier protein Smalonyltransferase (MCAMT). The malonyl-ACP enters into a series of condensation reactions with acyl-CoA under control of FAS enzymes, which leads to production of saturated FA 16:0-ACP. Finally, 16:0-ACP is desaturated to $16: 1-\mathrm{ACP}$ or elongated to 18:0-ACP, which is then desaturated to 18:1-ACP (Ohlrogge and Browse, 1995; He et al., 2020). The ratio between newly synthesized saturated and monounsaturated 
FAs is regulated by the activity of stromal soluble acyl-acyl carrier protein desaturases (AADs). The A. thaliana genome contains seven genes encoding AADs including FATTY ACID BIOSYNTHESIS2 (FAB2)/SUPPRESSOR OF SALICYLIC ACID INSENSITIVE2 (SSI2) and ACYL-ACYL CARRIER PROTEIN DESATURASES1-6 (AADs) (Kachroo et al., 2007). Depending on their regio- and substrate specificity, AADs belong to $\Delta 9$ stearoyl-ACP desaturases (SAD) responsible for desaturation 18:0-ACP to $18: 1-\mathrm{ACP}$ or $\Delta 9$ palmitoyl-ACP desaturases (PADs) involved in the production of 16:1-ACP from 16:0-ACP. Interestingly, analysis of single Arabidopsisaad mutants showed only slight changes in the FA composition, suggesting that AADs/SADs work redundantly in the production of 18:1-ACP. Indeed, recent studies demonstrated that four SAD desaturases-FAB2, AAD1, AAD5 and ADD6 play an important role in oleic acid biosynthesis in developing Arabidopsis seed (Kazaz et al., 2020).

\section{Fatty acid transporters-Transmembrane regulators of lipid homeostasis}

The majority (62\%) of de novo synthesized FAs are used for lipid synthesis in the ER via the eukaryotic pathway, whereas only $38 \%$ of FAs are incorporated into lipids in the prokaryotic pathway in the plastid (Li et al., 2016). Before the first step of lipid synthesis in the eukaryotic pathway, free FAs need to be first exported from the plastid to the ER (Fig. 1). Therefore, acyl-ACPs are first hydrolyzed by two different classes of acyl-ACP thioesterases (FAT) at the inner plastid envelope membrane (IE) to free FAs (FFAs). In general, type A of FAT (FATA) prefers 18:1-ACP as a substrate and type B of FAT (FATB) shows preferences towards 16:0-ACP and 18:0ACP (Salas and Ohlrogge, 2002; Bonaventure et al., 2003). In oilseeds, free 18:1 (oleic acid) is the major FA exported along with small amounts of 16:0 (palmitic acid) and 18:0 (stearic acid). 18:1 and its derivatives are significantly accumulated during Arabidopsis seed development and their production is important for proper embryo development and seed maturation. Loss of the function of FATB proteins is associated with reduction of saturated FAs in oilseeds of Arabidopsis (Bonaventure et al., 2003) or Camelina (Ozseyhan et al., 2018).

Recently, it was well demonstrated that FATTY ACID EXPORT 1 (FAX1) protein anchored in the IE of the plastid plays an important role as a FFAs transporter in Arabidopsis leaves and flowers (Li et al., 2015, 2016). Furthermore, detailed analysis of faxl mutant and $F A X 1$ overexpressing lines (FAXI ox) showed a significant decrease of TAG content in faxl leaves and flowers but not in seeds and increase of TAGs in both tissues in FAXl ox lines (Li et al., 2015). These findings support the role of FAX1 in plastid FFAs transport for TAGs biosynthesis in Arabidopsis vegetative tissues. In Arabidopsis, the FAX transporters family includes seven members but only two of them, FAX2 and FAX4, are highly expressed during early stage of seed development. Moreover, recently (Li et al., 2020) it was reported that fax 2 fax 4 seeds contain $30 \%$ less TAGs compared with wild type seeds. Thus, the loss of FAX2 and FAX4 function affects FFAs transport, resulting in a drop of TAGs biosynthesis during seed development. On the other hand, small differences in the relative content (mol\%) of TAG molecular species between these mutants and wild type suggest that other transporters may be also involved in TAGs synthesis in seeds (Li et al., 2020).

In the next step, FFAs are shuttled across the plastid outer envelope (OE) most likely via vectorial acylation by longchain acyl-CoA synthase (LACS), which catalyzes formation of acyl-CoA from FFAs (Fig. 1). In Arabidopsis, nine LACS proteins participate in lipid metabolism. However, overlapping function in the FAs transport from the plastid was reported only for three of them-LACS9, LACS1 and LACS4. Double mutants of lacs1 lacs 9 and lacs 4 lacs 9 showed an $11 \%$ and $27 \%$ FA decrease of seed TAGs, respectively (Zhao et al., 2010; Jessen et al., 2015). Homologs of LACS genes were also identified in the B. napus genome. BnLACS2 gene is highly expressed in developing seeds, regardless of whether expression was analyzed in high or low oil-content seeds (Ding et al., 2020). Overexpression of BnLACS2 in rapeseed was correlated with 6-8\% increase in oil content and significant enhancement in the abundance of 18:2, 20:0, 20:1 and 22:0. On the other hand, in BnLACS-RNAi transgenic plants, a decrease of 3 to $6 \%$ in oil content was observed compared to wild type plants. Thus, $B n$ LACS2 may be involved in the lipid metabolism during B. napus seed development and can be used as a potential target for genetic manipulation, which leads to increase of rapeseed oil content. Two homologs of Arabidopsis LACS9 and LACS8 genes-HaLACS1 and HaLACS2, respectively, were isolated from developing sunflower endosperm. Both genes exhibited high expression levels during sunflower seeds development (Aznar-Moreno et al., 2014). Based on their subcellular localization and substrate activity, it has been proposed that $\mathrm{HaLACS} 1$ might be involved in the activation of de novo synthesized FFAs in the plastid, whereas HaLACS2 could be involved in the acyl turnover of ER glycerolipids (Aznar-Moreno et al., 2014). FFAs activated to acyl-CoAs by the action of LACS are shuffled to the ER by the members of acyl-CoA binding proteins (ACBPs) (Fig. 1) (for review, see Raboanatahiry et al., 2018). Plant ACBPs are divided into four separate classes according to their size and domains: Class I small ACBPs, Class II ACBPs containing ankyrin repeats, Class III large ACBPs and Class IV ACBPs. In Arabidopsis, AtACBP6 belongs to class I, AtACBP1 and AtACBP2 to class II, AtACBP 3 to class III and AtACBP4 and AtACBP5 to class IV (Lung and Chye, 2016; Lai and Chye, 2021). Cytosolic ACBPs: AtACBP6, AtACBP4 and AtACBP5 have overlapping but distinct functions in Arabidopsis seed acyl-lipid homeostasis (Hsiao et al., 2014). All of them are expressed during seed development, however, their binding affinity for acylCoA esters is different. Recombinant rAtACBP6 displayed strong affinity with long-chain acyl-CoA (16- to 18-CoA), whereas the affinity of $\mathrm{rAtACBP} 4$ and $\mathrm{r} A t \mathrm{ACBP} 5$ was much weaker for these acyl-CoAs (Hsiao et al., 2014). Moreover, acbp6 mutant was reported to accumulate $18: 1-\mathrm{CoA}$ in the embryos and both 18:1-CoA and 18:2-CoA in the seedlings. Thus, these ACBPs seem to play the most important role in acyl-CoA transport during seed and seedling development among the other cytosolic AtACBPs (Hsiao et al., 2014). The ER-localized ACBPs: AtACBP1 and AtACBP2 are most probably involved in the transport of membrane-associated acyl pool from the ER to the plasma membrane (Raboanatahiry et al., 2018). Homologs of all Arabidopsis ACBPs genes were 
identified in B. napus genome (Raboanatahiry et al., 2015a, b). Class I BnACBP is a homolog of AtABCP6 and is highly expressed in developing embryos and cotyledons of seedlings (Hills et al., 1994; Engeseth et al., 1996). It was also demonstrated that recombinant $\mathrm{r} B n \mathrm{ACBP}$ possesses the ability to bind 16:0-CoA and 18:1-CoA and to enhance the activity of the Kennedy pathway enzymes such as glycerol-3phosphate acyltransferase (GPAT) (Brown et al., 1998). So far, only few more homologs of AtABCP were identified and fully characterized in other oilseed crops. Strong expression in developing sunflower seeds was reported for genes encoding HaACBP6, a homolog of AtABCP6 and BnACBP, (Aznar-Moreno et al., 2016) and HaACBP1 belonging to Class II ACBPs (Aznar-Moreno et al., 2020). rHaACBP6 protein has been shown to have a higher affinity towards 16:0CoA, 18:0-CoA and 18:1-CoA rather than 18:2-CoA. Ability of $\mathrm{rHaACBP} 6$ to bind different species of PC (dipalmitoylPC, dioleoyl-PC and dilinoleoyl-PC) suggests that this protein can be associated with TAGs biosynthesis (AznarMoreno et al., 2016). In the following studies, rHaACBP1 displayed a high affinity to $16: 0-\mathrm{CoA}$ and $18: 0-\mathrm{CoA}$ and lower affinity to $18: 1-\mathrm{CoA}$ and $18: 2-\mathrm{CoA}$. Similarly to $\mathrm{rHaACBP} 6, \mathrm{rHaACBP} 1$ has ability to bind to dioleoyl-PC and dilinoleoyl-PC (Aznar-Moreno et al., 2020). The high affinity level of both proteins towards the products of de novo FAs synthesis clearly indicates their essential role in the transport and trafficking of acyl-CoAs in sunflower developing seeds. Based on in silico analysis of ACBPs, 11 members of soybean $G m$ ACBPs were identified and classified into four classes (Azlan et al., 2021). Two genes encoding GmACBP1 and $G m A C B P 2$ proteins from Class I of ACBPs showed elevated expression during soybean seed development. However, more detailed analyses are needed in order to characterize the function of all members of soybean ACBPs in lipid trafficking in seeds.

In addition to ACBPs proteins, Arabidopsis AtABCA9 that belongs to ATP-binding cassette (ABC) transporter subfamily A, was characterized as a FA/acyl-CoA transporter which mediates transport of FAs into the ER (Kim et al., 2013). AtABCA9 is localized in the ER and is highly expressed during seed development. Seeds of abca9 mutants were characterized by reduced size, abnormal morphology and lower levels of TAGs, whereas the overexpression of AtABCA9 increased seed TAG content when compared to wild type plants (Kim et al., 2013). Moreover, feeding experiments showed significantly lower incorporation of FAs into TAGs in $a b c a 9$ seeds than in the wild type. Thus, it was concluded that AtABCA9 functions as a transporter of acyl-CoAs into the ER, where they can be used as substrates for TAGs synthesis. Interestingly, loss of function or overexpression of different transporters very often leads to the changes in the seed oil content. Therefore, use of lipid transporters could also be one of the strategies to increase oil content in seeds. Recently, it was demonstrated that overexpression of Arabidopsis $F A X 1$ and $A B C A 9$ affects oil production in Camelina seeds (Cai et al., 2021). Moreover, simultaneous overexpression of both genes had a better effect on enhancing oil production in seeds than overexpression of AtFAX1 and AtABCA9 individually (Cai et al., 2021).

\section{TAG synthesis is not a simple linear pathway}

After being transported from the plastid to the ER, the acylCoAs are utilized for TAGs or membrane lipid synthesis. TAGs, major storage lipids in oilseeds, can be synthesized via different pathways. The most common pathway to assembly FAs into TAGs is the acyl-CoA-dependent Kennedy pathway (Fig. 2). In this pathway, acyl-CoAs are incorporated into the sn-1 and sn-2 positions of glycerol-3-phosphate (G3P) by G3P acyltransferase (GPAT) and lysophosphatidic acid acyltransferase (LPAAT), respectively, to form phosphatidic acid (PA). Next, a phosphate group is removed from PA by phosphatidic acid phosphatase (PAP) and the resulting diacylglycerol (DAG) is acylated on the sn-3 position by acyl-CoA: diacylglycerol acyltransferase (DGAT) (Chapman and Ohlrogge, 2012). This reaction completes the de novo synthesis of TAGs and indicates DGATs as the key enzymes for oil accumulation in oilseeds. Plant DGATs identified so far belong to three distinct families. DGAT1 and DGAT2, which are integral ER proteins and play non-redundant roles in TAGs biosynthesis, and DGAT3 being a cytosolic enzyme (Turchetto-Zolet et al., 2016). DGAT1 is a key enzyme involved in TAGs formation in developing seeds. Disruption of Arabidopsis DGAT1 resulted in decrease in seed TAG content and changes in their profile, characterized by the higher level of 18:3 when compared to wild type plants (Katavic et al., 1995; Routaboul et al., 1999; Zou et al., 1999). In turn, its overexpression resulted in increased seed oil accumulation (Jako et al., 2001). In contrast, dgat 2 mutation had no impact on seed TAGs deposition (Zhang et al., 2009). However, later studies on plants accumulating unusual FAs showed that DGAT2s are responsible for incorporation of unusual FAs into TAGs (Li et al., 2010), such as ricinoleic acid in Ricinus communis (Burgal et al., 2008) or eleosteric acid in Vernicia fordii (Shockey et al., 2006). Studies on B. napus revealed that DGAT2s isoforms have different substrate specificities and display highly variable activity towards $18: 3$ and from very little to high activity towards 22:1 (Demski et al., 2019). Interestingly, Camelina sativa DGAT1 and DGAT2 have complementary substrate specificities. CsDGAT1 possesses high specificity towards acyl donors with saturated and monounsaturated FAs, whereas CsDGAT2 prefers acyl acceptors containing only polyunsaturated FAs (Lager et al., 2020). The third family of DGAT enzymes, DGAT3 consists of soluble cytosolic enzymes identified for the first time in peanut (Saha et al., 2006). In Arabidopsis, DGAT3 is involved in recycling of 18:2 and 18:3 FAs into TAGs when storage lipids are not catabolized (Hernández et al., 2012). Recently, it was shown that Arabidopsis DGAT3 is a metalloprotein with the ability to synthetise TAGs in vitro (Aymé et al., 2018). Among three DGAT3 genes identified in C. sativa, CsDGAT3-3 was highly expressed in developing seeds. Moreover, overexpression of CSDGAT3-3 leads to accumulation of TAGs in yeast and Nicotiana benthamiana leaves. CsDGAT3-3 showed preference towards unsaturated FAs, particularly eicosenoic acid (20:1n-9) (Gao et al., 2021). Since the terminal step of the Kennedy pathway is one of the rate-limiting steps of TAGs synthesis, DGATs are one of the main targets of genetic 


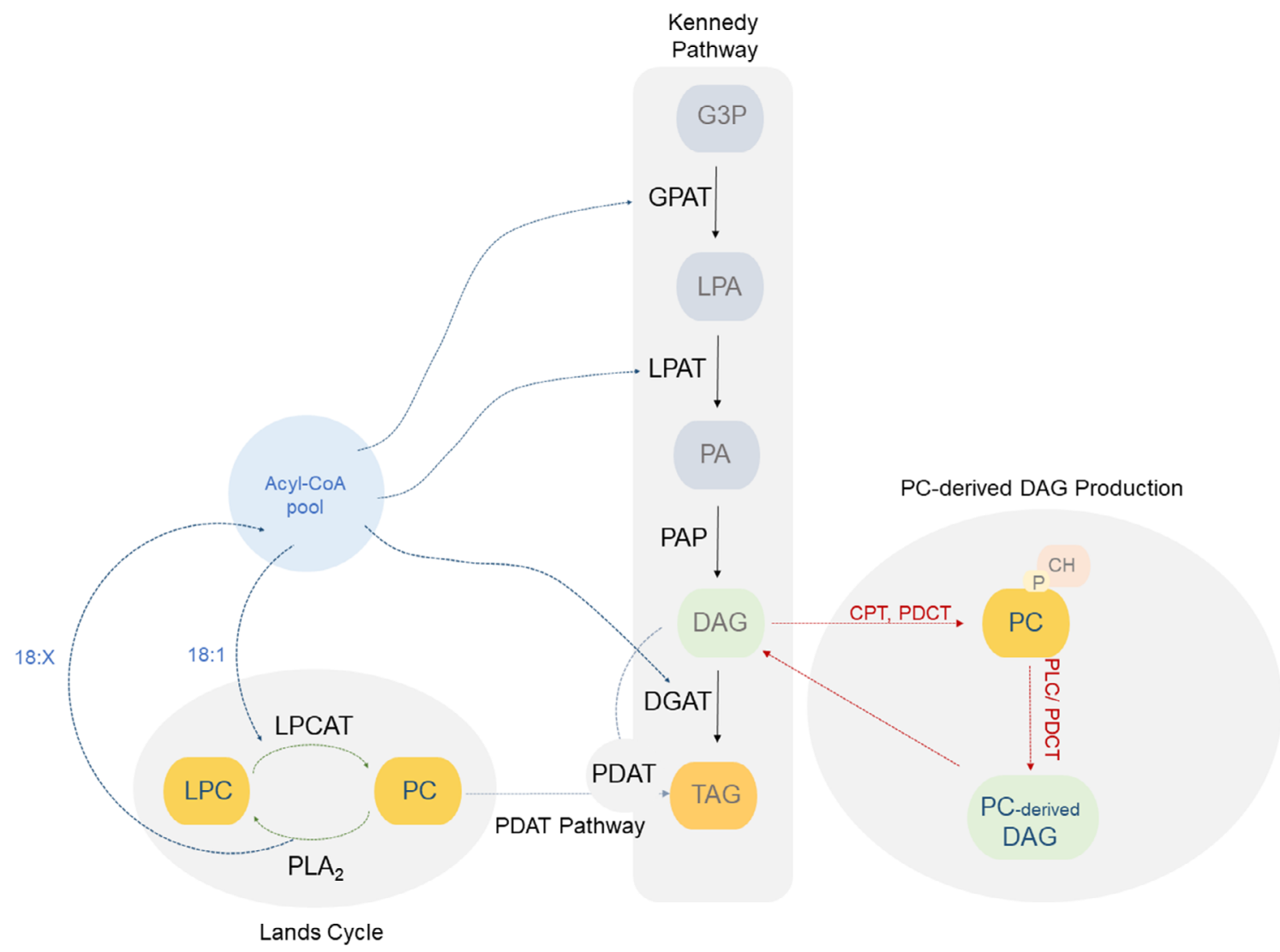

Fig. 2. Schematic presentation of ER localized TAG formation pathways in oilseeds. Acyl-CoAs from the plastid are exported to the cytosol and used as substrates in glycerol transesterification reactions of the Kennedy pathway. The final product of these reactions, TAGs formed by esterification of DAG by DGAT enzyme. DAGs can also be transformed to TAGs by the action of PDAT enzyme, which uses PC as the acyl donor (PDAT pathway). The cycles of deacylation/reacylation of PC/LPC catalyzed by phospholipases (PLA2) and Acyl-CoA: Lysophosphatidylcholine Acyltransferase (LPCAT), respectively, deliver acyl-CoAs. These reactions are known as the Lands cycle and produce new or modified acyl-CoAs. PC can also serve as a donor of DAG moiety used for synthesis of TAGs (PC-derived DAG production). Detailed description of the presented pathway can be found in the text. Abbreviations: CoA: coenzyme A; CPT: CDP-choline: diacylglycerol phosphotransferase; DAG: diacylglycerol; DGAT: acyl-CoA: diacylglycerol acyltransferase; G3P: glycerol 3 phosphate; GPAT: acyl-CoA: glycerol-3-phosphate acyltransferase; LPA: lysophosphatidic acid; LPAT: acyl-CoA: lysophosphatidic acid acyltransferase; LPCAT: acyl-CoA: lysophosphatidylcholine acyltransferase; PA: phosphatidic acid; PAP: phosphatidic acid phosphatase; PC: phosphatidylcholine; PDCT: phosphatidylcholine diacylglycerol cholinephosphotransferase; PLC: phospholipase C; PLA2: phospholipase A2; TAG: triacylglycerol.

manipulations towards increasing oil production in plants (reviewed in $\mathrm{Xu}$ et al., 2018). Overexpression of DGAT enzymes led to enhanced oil deposition in rapeseed (Weselake et al., 2008; Taylor et al., 2009), Jatropha curcas (Zhang et al., 2021), soybean (Lardizabal et al., 2008; Roesler et al., 2016), cottonseed (Wu et al., 2021) and maize (Oakes et al., 2011).

TAGs synthesis is not a simple linear pathway as TAGs composition depends on the flux of acyl groups in and out of phosphatidylcholine (PC) prior FAs incorporation to the TAGs. Most de novo 18:1-CoAs are first incorporated into membrane PC and then desaturated by the action of fatty acid desaturases. FAD2 ( $\omega-6$ fatty acid desaturase) catalyzes the conversion of 18:1-CoA into 18:2-PC, which is then desaturated to $18: 3-\mathrm{PC}$ by FAD3 ( $\omega-3$ fatty acid desaturase) (Lou et al., 2014). By the action of FAD2 and FAD3 most of oil crop seeds contain high concentrations of polyunsaturated FAs (PUFAs), such as 18:2 and 18:3 (Dar et al., 2017; Du et al.,
2018). However, the high concentration of PUFAs reduces the oxidative stability of oil and lowers its quality. Thus, the recent genetic engineering strategies focus on generation of transgenic seeds containing reduced amount of PUFAs and higher content of monounsaturated fatty acids (MUFAs), such as oleic acid. RNAi and CRISPR-Cas9 technologies were employed to create transgenic plants with mutated FAD2 and FAD3. CRISPR-Cas9 editing of the soybean GmFAD2-1A, GmFAD2-1B and GmFAD2-2 led to relevant increase in 18:1 and decrease in 18:2 content (Al Amin et al., 2019; Do et al., 2019). Similarly, the seeds of Camelina triple CsFAD2 knockout mutants generated by CRISPR-Cas9 system showed reduced content of total PUFAs and significant increase in MUFA levels reaching $80 \%$ of dry weight. Unfortunately, the transgenic lines showed inhibited growth and produced less seeds compared to wild type plants (Lee et al., 2021). However, Camelina plants expressing only one copy of 
CsFAD2 gene showed normal growth rates and increased levels of MUFA reaching $60 \%$ of dry weight (Lee et al., 2021). Acyl-CoAs can be also elongated by fatty acyl elongase complex, which leads to production of very long-chain FAs (VLCFAs). FAE1 gene encodes 3-ketoacyl-CoA synthase (KCS), which catalyzes the first rate-limiting step of acyl-CoA elongation and is commonly used to modify acyl-CoA pool towards higher levels of VLCFAs (Mietkiewska et al., 2007; Ma et al., 2021).

Acyl-editing mechanisms, including the land cycle or reversible LPCAT (acyl-CoA: lysophosphatidylcholine acyltransferase) activity, are responsible for exchange of FAs between PC and acyl-CoA pool (Fig. 2). In the Land cycle, FAs are released from $\mathrm{PC}$ by the action of phospholipase A2 (PLA2), which leads to production of lysophosphatidylcholine (LPC) and FFAs. Before entering the acyl-CoA pool, FFAs are activated to acyl-CoAs by LACS (Fig. 1). Meantime, reacyclation of LPC and incorporation of 18:1 acyl-CoAs are catalyzed by the LPCAT (see review Bates, 2016). On the other hand, the reverse activity of LPCAT leads to a direct transfer of FAs from PC into acyl-CoA pool (Bates, 2016). A third pathway of TAGs synthesis implies the acyl flux through PC via acyl-CoA-independent mechanism governed by a phospholipid: diacylglycerol acyltransferase (PDAT). This enzyme catalyses an acyl transfer from sn-2 position of $\mathrm{PC}$ to DAG leading to formation of TAGs (Dahlqvist et al., 2000). PDAT contribution to TAGs biosynthesis in seeds is still not well understood. In the PDAT knockout lines of Arabidopsis no changes in seed TAG content were observed (Mhaske et al., 2005), which was attributed to the ability of DGAT1 to fully compensate for the loss of PDAT activity (Zhang et al., 2009). Since a double dgat1 pdat mutant produced sterile pollen, downregulation of PDAT in dgatl background was achieved using RNAi silencing and resulted in reduction of seed oil content up to $80 \%$ and impaired embryo development (Zhang et al., 2009). The ratio between PDAT and DGAT activities differs among oilseed plants. For example, it was significantly higher in membrane fractions obtained from safflower developing seeds compared to sunflower. However, the specificities of PDATs from both species were similar as in both cases the substrate preference for 18:2-PC over 18:1-PC as an acyl donor was observed (Banas et al., 2013). Interestingly, overexpression of $C S P D A T$ significantly increased 18:2 on the expense of 18:3 and 20:1 in transgenic $C$. sativa seeds (Marmon et al., 2017). In addition, recent studies on $C s$ PDAT showed that its activity depends on available DAG species. In in vitro analysis of CsPDAT specificity performed with di-18:2-DAG, 18:3-PC was rather preferred than 18:2PC, whereas with di-18:3-DAG the opposite pattern was observed (Lager et al., 2020). It has also been shown that PDATs play an important role in the incorporation of unusual FAs into TAGs. PDATs from castor bean or Crepis palaestina showed a preference for phospholipids containing hydroxylated and epoxidated FAs, typical for these plant species (Dahlqvist et al., 2000). Co-expression of the gene encoding seed-specific castor bean fatty acid hydroxylase (RcFAH12) together with RcPDAT enhanced accumulation of hydroxy FAs up to $27 \%$ in Arabidopsis seeds (Kim et al., 2011; van Erp et al., 2011). Finally, production of TAGs implicates the flux of DAG moieties between DAGs synthesized by the Kennedy pathway and PC. De novo synthesized DAGs are incorporated into PC by the action of CDP-choline: diacylglycerol cholinephosphotransferase (CPT) and PC-derived DAGs are generated by the cleavage of PC by phospholipase C (PLC) (Bates, 2016). The phosphatidylcholine: 1,2-sn-diacylglycerol choline phosphotransferase (PDCT) is another enzyme involved in the transfer of the phosphocholine headgroup between DAG and PC (Lu et al., 2009). Recently, the interactions between $A t \mathrm{DGAT} 1$ and $A t \mathrm{LPCAT} 2, A t \mathrm{PDCT}$ and AtPDAT1 were confirmed in yeast two-hybrid system (Regmi et al., 2020). The interaction between these enzymes supports the hypothesis about the crosstalk between different metabolic networks leading finally to TAGs synthesis. This finding proves as well that AtDGAT1 uses both PC-derived acyl-CoA and DAG as substrates (Regmi et al., 2020).

\section{Seed lipid droplets - The final destination for TAGs}

In seeds, the TAGs synthesized by the above mentioned enzymes are packed into specialized organelles called lipid droplets (LDs), which consist of a neutral lipid core surrounded by a phospholipid monolayer harbouring specific structural proteins, such as oleosins, caleosins and steroleosins (recently reviewed in Huang, 2018; Shao et al., 2019; Zienkiewicz and Zienkiewicz, 2020). Oleosins are small proteins $(15-30 \mathrm{kDa})$ that contain cytosolic-facing $\mathrm{N}$ - and Ctermini and a large hydrophobic domain essential for their targeting to LDs. Oleosins play an important role in the regulation of LDs size and stability. In the A. thaliana genome, 16 oleosin-encoding genes have been identified and five of them are specifically expressed in seeds (Kim et al., 2002). AtOLE1 accounts for approximately $65 \%$ of the LD-associated proteins in seeds, while AtOLE2 and AtOLE4 together represent around $30 \%$ of the LDs proteins. AtOLE3 and AtOLE5 are less abundant in the seed LD fraction (Siloto et al., 2006; Miquel et al., 2014; Huang, 2018). Caleosins comprise an N-terminal hydrophilic domain with an EF-hand calcium binding motif, a central hydrophobic region containing a proline knot that anchors the protein to the LDs membrane and a C-terminal hydrophilic region with several phosphorylation sites (Hanano et al., 2006; Purkrtova et al., 2007). Among eight Arabidopsis caleosin-encoding genes, AtCLO1 and AtCLO2 are expressed abundantly in developing seeds (Naested et al., 2000; Poxleitner et al., 2006). Steroleosins are hydroxysteroid dehydrogenases (HSD) involved in metabolism of brassinosteroids. A sterol-binding dehydrogenase/reductase domain is localized on the C-terminus of the protein, whereas N-terminal hydrophobic region with a proline knob motif anchors the protein to the LDs membrane (Lin and Tzen, 2004; d'Andréa et al., 2007). Other LD-associated proteins, such as oil body associated protein 1 (OBAP1), LDAP-interacting protein (LDIP) or different low-abundance LD proteins were also identified in oilseeds (López-Ribera et al., 2014; Pyc et al., 2017; Kretzschmar et al., 2020).

The mechanism of LD biogenesis in plants (reviewed in Chapman and Ohlrogge, 2012; Ischebeck et al., 2020) is still not well characterised. LD formation starts on the ER membrane. Storage lipids are synthesised by lipid biosynthetic enzymes associated with the ER and accumulate between the two leaflets of the ER bilayer to form lens-like structures. 
Table 1. Approximate fatty acid composition of TAGs from selected oilseeds. The values are presented as \% of total fatty acids (TFAs) and the given ranges represent the data from diverse literature sources (soybean: Kanai et al., 2019; Vogel et al., 2019; rapeseed: Baud and Lepiniec, 2010; Lu et al., 2020; Arabidopsis: Li et al., 2006; Kelly, 2018; Camelina: Ciurescu et al., 2016; Ozseyhan et al., 2018).

\begin{tabular}{lcccc}
\hline Fatty acid (\% TFA) & Soybean & Rapeseed & Arabidopsis \\
\hline $16: 0$ & $10-13$ & $3-4$ & $7-8.5$ & $3-7$ \\
$18: 0$ & $3-5$ & $1-2$ & $3-3.5$ & $1.5-4$ \\
$18: 1$ & $18-24$ & $16-24$ & $27-29$ & 18.5 \\
$18: 2$ & $53-55$ & $13-16$ & $17-19$ & $18-19$ \\
$18: 3$ & $8-13$ & $7-9$ & $1.7-2$ & $33-37$ \\
$20: 0$ & - & $1-2$ & $17-20$ & $12-13$ \\
$20: 1$ & - & $9-15$ & - & $1.4-1.7$ \\
$20: 2$ & - & - & - & $0-1$ \\
$20: 4$ & - & - & $1.5-2$ & $2.5-5$ \\
$22: 1$ & - & $40-45$ & \\
\hline
\end{tabular}

Oleosins are co-translationally inserted into the ER and move to nascent LDs. Mature LDs detach from the ER or are formed by the fusion of nascent small LDs (Chapman and Ohlrogge, 2012; Huang, 2018). To date, several proteins orchestrating LDs formation have been identified. Among them, SEIPINs play a crucial role in controlling the number and size of LDs. In the $A$. thaliana genome, there are three SEIPIN homologs (Cai et al., 2015). SEIPIN2 and SEIPIN3-deficient mutants produced enlarged LDs (Taurino et al., 2018), whereas silencing of SEIPIN1 led to reduced seed size and lower oil accumulation (Cai et al., 2015). In plants overexpressing SEIPIN1, an increased number of LDs and higher neutral lipid content compared to the wild type was observed (Cai et al., 2015). SEIPINs are localized at ER-LD junctions and cooperate with other proteins from LD biogenesis machinery (Greer et al., 2020). A series of recent studies identified SEIPIN-interaction partners, which included the vesicleassociated membrane protein (VAMP)-associated protein (VAP) family member $A t$ VAP27-1 (Greer et al., 2020), lipid droplet-associated protein (LDAP) and LDAP-Interacting Protein (LDIP) (Pyc et al., 2021). Based on these findings, Pyc et al. (2021) proposed a new and more detailed model of LD biogenesis.

Overexpression of different genes encoding LD-associated proteins can lead to enhanced LDs assembly. In rice, the expression of two soybean oleosin genes under an embryospecific promoter resulted in smaller and more numerous LDs compared to the wild type and increased the seed lipid content up to $46 \%$ (Liu et al., 2013). It was also shown that mouse fatstorage-inducing transmembrane protein (FIT2), which is involved in LD biogenesis, can promote LDs accumulation in Arabidopsis seeds (Cai et al., 2017). The possibility of enhancing LDs assembly via overexpression of genes encoding plant LD-associated proteins was investigated in yeasts (Froissard et al., 2009; Jacquier et al., 2013) and microalgae (Zulu et al., 2017). Yeasts were engineered for the accumulation of increased neutral lipid levels by promoting LDs formation by introducing genes encoding LDs proteins, such as AtOLE1 (Jacquier et al., 2013) or AtCLO1 (Froissard et al., 2009).

\section{Endosperm or embryo-This is a question}

Depending on species, LDs accumulate in different parts of the seeds. Some of the oilseed crops, like castor bean store TAGs mainly in endosperm, whereas in rapeseed, Arabidopsis, soybean or sunflower most of these lipids are present in embryo (Baud and Lepiniec, 2010). The seed oil content varies between diverse species of oil crops and ranges from about $20 \%$ for soybeans (Clemente and Cahoon, 2009) to over $40 \%$ for sunflowers or canola (rapeseed) (Matthaus et al., 2016; Premnath et al., 2016). Importantly, the oilseed crops vary not only in the seed oil content but also in its composition (Tab. 1). The most common FAs found in seed TAGs include palmitic acid (16:0), stearic acid (18:0), oleic acid (18:1), linoleic acid (18:2) and $\alpha$-linolenic acid (18:3) (Voelker and Kinney, 2001). However, many other FAs have been described in TAGs accumulated in the seeds of diverse Angiosperms. These include longer FAs composed of 20 to 24 carbon atoms identified in Brassicaceae family, like gondoic acid (20:1) or erucic acid (22:1) as well as modified common FAs, like hydroxylated ricinoleic acid $(18: 1-\mathrm{OH})$ found in castor bean (Baud and Lepiniec, 2010). Interestingly, the studies of Woodfield et al. (2017) in B. napus seeds by using matrixassisted laser desorption/ionization mass spectrometry (MALDI-MS) revealed highly diverse distribution patterns of TAGs molecular species between different tissues of the seed. For example, the authors showed that palmitatecontaining PC and TAGs are particularly abundant in the embryonic axis. In contrast, seed coat/aleurone layer is mostly enriched in lipid species containing 18:2 and 18:3 (Woodfield et al., 2017). Such heterogeneous spatial distribution patterns of lipids likely indicate differences in lipid metabolic pathways between diverse tissues of the seed.

\section{Wax esters-Unique seed storage lipids}

Wax esters (WEs) are unusual type of storage lipids in plants. They are accumulated in seeds of Simmondsia chinensis (jojoba), a perennial desert shrub native to North America. 
Jojoba oil accounts for approximately $60 \%$ of the seed weight and contains WEs composed of very long-chain (C20, C22, and C24) monounsaturated FAs and alcohols (Miwa, 1971; Ohlrogge et al., 1978). WEs are synthesised in developing embryos by a three-step pathway, which involves the activity of fatty acid elongase (FAE), fatty acyl reductase (FAR) and wax synthase (WS). FAE is a complex of four membraneassociated enzymes with activities similar to FAS, which elongate 18:1-CoA by two carbons producing 20:1-CoA, 22:1-CoA and 24:1-CoA (Lardizabal et al., 2000). Formed long-chain acyl-CoAs are further reduced by FAR to corresponding alcohols (Metz et al., 2000). The final step of WE synthesis is catalyzed by WS, fatty acyl-CoA: fatty alcohol acyltransferase, which esterifies long-chain fatty acyl-CoAs to long-chain fatty alcohols (Lardizabal et al., 2000).

WEs are stored in so called wax bodies with a structure resembling plant LDs (Rost and Paterson, 1978). Wax bodies are formed at about 55-60 days after pollination and WE content increases during the entire maturation stage (Benzioni et al., 2007). Analysis of MS/MS data for polypeptides isolated from the wax body fraction resulted in matches with oleosins from castor bean and grape (Rajangam et al., 2013). In the recently published jojoba genome, the sequences of six oleosins, one caleosin and two lipid droplet-associated protein (LDAPs) have been identified. Based on the abundance of LDAP1 in wax bodies localized in cotyledons, it was suggested that this protein may be important for the proper packaging of WEs (Sturtevant et al., 2020). Jojoba WEs have a variety of industrial applications. However, due to the expensive and limited production of jojoba oil, they are mainly used as a component of pharmaceuticals and cosmetics. Metabolic engineering approaches enabled the transfer of the jojoba WEs biosynthetic pathway to bacteria (Kalscheuer et al., 2006), yeast (Wenning et al., 2017, 2019) and plants (Iven et al., 2016; Li et al., 2019; Yu et al., 2018). Jojoba-like WEs were produced in TAG-accumulating non-food Brassicaceae species, such as Arabidopsis, C. sativa, Brassica carinata, Crambe abyssinica (Iven et al., 2016; Zhu et al., 2016) and Lepidium campestre (Ivarson et al., 2017), reaching up to $100 \mathrm{mg}$ of WE per $1 \mathrm{~g}$ of seeds. Such engineered oilseed crops are promising platforms for future renewable and sustainable WEs production for commercial purposes.

\section{Transcriptional factors as puppet masters}

Accumulating evidence suggests that a transcriptional cascade of diverse transcription factors (TFs) controls seed oil deposition (Baud and Lepiniec, 2010). The master regulator of FAs biosynthesis is WRINKLED1 (WRI1), a member of the APETALA2 (AP2) family of transcription factors (Kong and Ma, 2018). The Arabidopsis wril mutant produced wrinkled seeds with reduced oil content by up to $80 \%$ when compared to wild type plants (Focks and Benning, 1998; Cernac and Benning, 2004). In turn, overexpression of AtWRI1 or other WRI1 orthologs elevated oil content in transgenic seeds (Cernac and Benning, 2004; Liu et al., 2010; An and Suh, 2015; Vogel et al., 2019). AtWRI1 regulates the transcription of multiple genes directly involved in glycolytic and FAs biosynthesis pathways such as ACP3, KASI or FAD2. The activation of AtWRII depends on the action of LEAFY
COTYLEDON1 (LEC1), LEAFY COTYLEDON2 (LEC2) and FUSCA3 (FUS3) TFs located upstream of AtWRI1 in the regulatory network (Baud et al., 2007; Mu et al., 2008). These TFs together with ABSCISIC ACID INSENSITIVE 3 (ABI3) are known as a LAFL proteins (LEC2, ABI3, FUS3, LEC1) (Boulard et al., 2017; Tian et al., 2020). LAFL TFs play an important role in different aspects of seed development, including oil accumulation. In addition to positive regulators of FAs synthesis in seeds, few negative regulators of oil synthesis were identified as well. MYB89 TF was reported as an important repressor of AtWRI1 (Li et al., 2017). In turn, TRANSPARENT TESTA8 (TT8) as a repressor of Arabidopsis $L E C 1, L E C 2$ and $F U S 3$ expression (Chen et al., 2014) and TRANSPARENT TESTA GLABRA1 (TTG1) negatively regulates the transcription of AtFUS3 (Chen et al., 2015). In the maturating endosperm of Arabidopsis, the transcription of two PADs desaturases $A A D 2$ and $A A D 3$ is regulated by two TFs: MYB115 and MYB118 (Troncoso-Ponce et al., 2016a). While LEC2 activates the transcription of both TFs, MYB18 negatively regulates the transcription of $L E C 2$. Both MYBs work simultaneously in regulation of $A A D 2$ and $A A D 3$ transcription (Troncoso-Ponce et al., 2016a). In addition to transcriptional regulation of the genes involved in FAs synthesis, Lee et al. (2018) reported that R2R3-type MYB96 TF activates expression of AtPDAT1 and AtDGAT1. Overexpression of $M Y B 96$ resulted in higher content of accumulated TAGs in seeds, while in myb96-deficient mutant the deposition of TAGs was lower compared to the wild type (Lee et al., 2018).

\section{Best supporting characters-Sterols and sphingolipids}

In general, sterols are isoprenoid-derived lipids playing essential role in membrane fluidity and permeability and serve as precursors for brassnosteroids synthesis (Valitova et al., 2016; Bajguz et al., 2020). Sterols, together with sphingolipids, form membrane microdomains called lipid rafts, which are involved in diverse cellular processes (Xu et al., 2001). In plants, cycloartenol serves as a common substrate for sterols synthesis including cholesterol, sitosterol, stigmasterol and campesterol. Interestingly, during Arabidopsis seed development, expression of the genes encoding enzymes responsible for sterol biosynthesis is positively correlated with the expression of the genes associated with FAs and TAGs biosynthesis (Yu et al., 2021). Moreover, accumulation of significant levels of total sterols is observed in oilseeds (Harker et al., 2003). On the other hand, storage form of sterols-sterol esters are together with TAGs accumulated in seed LDs. Recently, Yu et al. (2021) revealed that mutations in sterol synthesis pathway in A. thaliana resulted not only in reduced seed TAG content and seed yield, but also in the presence of enlarged, but less numerous LDs. Moreover, the impairment of sterol synthesis was also accompanied by the reduced levels of seed oleosin. Based on their results, the authors suggested that sterols might be involved in regulating essential physicochemical properties of the ER membrane required for a proper LDs formation and/or controlling the recruitment of LDassociated proteins necessary for formation of LDs during seed development (Yu et al., 2021). 
Sphingolipids, together with sterols are structural and functional membrane lipids. In plants, sphingolipids are classified into four main classes: 1) long-chain base (LCBs), 2) ceramides (Cer), 3) glucosylceramides (GluCer) and 4) glycosyl inositolphosphoceramides (GIPCs) (Michaelson et al., 2016). Detailed sphingolipid profiling was performed on Arabidopsis and Camelina seeds and oil (Tellier et al., 2014). Interestingly, Cer and hCer (hydroxylated Cer) were accumulated in both, seed and oil, meanwhile GluCer and GIPCs were absent in the oil fraction. Moreover, Arabidopsis seeds are characterized by the accumulation of the specific GIPCs such as NH2-GIPCs and series B GIPCs. Regarding to Camelina seeds, less Cers and hCers were observed when compared to Arabidopsis seeds, while both Camelina and Arabidopsis seeds showed comparable levels of GluCer, GIPCs or NH2-GIPCs (Tellier et al., 2014). Significant decrease in GlcCer and Cer content was observed during soybean seed development (Wang et al., 2006). Recently, it was demonstrated that loss of serine palmitoyltransferase (SPT) regulation in the CRISPR/Cas9 knockout mutant of OROSOMUCOID-LIKE PROTEINS (ORMs) leads to production of nonviable and abnormal seeds (Gonzalez-Solis et al., 2020). The analysis of lipid content demonstrated that TAG content was reduced in abnormal seeds up to $85-95 \%$, when compared to wild type seeds. Moreover, the reduction in TAG content was accompanied by a high concentration of ceramides in the abnormal seeds (Gonzalez-Solis et al., 2020). These results suggest that homeostasis in sphingolipid content is essential for proper seed development, however, the progress in understanding of this phenomena is still in its infancy. Overall, our knowledge on both sterol and sphingolipid involvement in oil accumulation in seeds is still scarce and more research is needed in order to elucidate the role of nonTAG-related compounds in oilseed lipid metabolism.

\section{Concluding remarks}

Although seed lipid metabolism is thus far the best characterized among all the plant tissues and organs, many questions remain to be elucidated. Definitively, sequencing of the oil crops genomes boosted the progress in our understanding of this phenomena and has set the stage for identifying and characterizing genes and their protein products involved in diverse aspects of lipid metabolism. The research of the last decade only delivered plenty of valuable data on transcriptional network governing TAGs synthesis in oilseeds, novel intracellular transporters of FAs or on the functional nature of lipid modifying enzymes. Moreover, cutting-edge lipidomic profiling of oilseeds and mapping of diverse lipids in situ by MALSI-MSI continuously deliver big data sets on the complexity of lipids in oilseeds. This knowledge is of essential meaning not only to fill the gaps in our understanding of the key lipid pathways existing in plant cells, but also for development of biotechnological and genetic engineering of oil crops in order to increase their energetic density. The latter aspect is currently extremely important because of negative climatic changes occurring currently on Earth, progressive reduction of arable land and constantly growing human population, which together could face us with a global food crisis in the nearest future. Thus, future work should focus mechanistic studies on oilseed lipid metabolism, combining diverse omics technologies, molecular biology and biotechnology. Such a combined approach will guarantee the substantial progress in deciphering yet unknown but crucial avenues that underlie oil synthesis in seeds.

Acknowledgments. This work benefited from the support of the Polish National Science Centre (Grants UMO-2019/34/E/ NZ1/00023 and UMO-2019/35/B/NZ9/01075). MM has received funding from the European Union's Horizon 2020 research and innovation programme under the Marie Skłodowska-Curie grant agreement No.847693. MM acknowledges the support from the REWIRE (REinforcing Women In Research) Project at the University of Vienna.

Conflicts of interest. The authors declare that they have no conflicts of interest in relation to this article.

\section{References}

Al Amin N, Ahmad N, Wu N, et al. 2019. CRISPR-Cas9 mediated targeted disruption of FAD2-2 microsomal omega- 6 desaturase in soybean (Glycine max L.). BMC Biotechnol 19: 9.

An D, Suh MC. 2015. Overexpression of Arabidopsis WRII enhanced seed mass and storage oil content in Camelina sativa. Plant Biotechnol R 9: 137-148.

Aymé L, Arragain S, Canonge M, et al. 2018. Arabidopsis thaliana DGAT3 is a [2fe-2s] protein involved in TAG biosynthesis. Sci Rep 8: 17254.

Azlan NS, Guo ZH, Yung WS, et al. 2021. In silico analysis of acylCoA-binding protein expression in soybean. Front Plant Sci 12: 646938.

Aznar-Moreno JA, Venegas Calerón M, Martínez-Force E, et al. 2014. Sunflower (Helianthus annuus) long-chain acyl-coenzyme A synthetases expressed at high levels in developing seeds. Physiol Plant 150: 363-373.

Aznar-Moreno JA, Venegas-Calerón M, Du ZY, et al. 2016. Characterization of a small acyl-CoA-binding protein (ACBP) from Helianthus annuus L. and its binding affinities. Plant Physiol Biochem 102: 141-150.

Aznar-Moreno JA, Venegas-Calerón M, Du ZY, et al. 2020. Characterization and function of a sunflower (Helianthus annuus L.) class II acyl-CoA-binding protein. Plant Sci 300: 110630.

Bajguz A, Chmur M, Gruszka D. 2020. Comprehensive overview of the brassinosteroid biosynthesis pathways: Substrates, products, inhibitors, and connections. Front Plant Sci 11: 1034.

Banas W, Sanchez Garcia A, Banas A, Stymne S. 2013. Activities of acyl-CoA: Diacylglycerol acyltransferase (DGAT) and phospholipid: Diacylglycerol acyltransferase (PDAT) in microsomal preparations of developing sunflower and safflower seeds. Planta 237: 1627-1636.

Bates PD. 2016. Understanding the control of acyl flux through the lipid metabolic network of plant oil biosynthesis. Biochim Biophys Acta 1861: 1214-1225.

Baud S, Mendoza MS, To A, Harscoët E, Lepiniec L, Dubreucq B. 2007. WRINKLED1 specifies the regulatory action of LEAFY COTYLEDON2 towards fatty acid metabolism during seed maturation in Arabidopsis. Plant J 50: 825-838.

Baud S, Dubreucq B, Miquel M, Rochat C, Lepiniec L. 2008. Storage reserve accumulation in Arabidopsis: Metabolic and developmental control of seed filling. Arabidopsis Book 6: e0113.

Baud S, Lepiniec L. 2010. Physiological and developmental regulation of seed oil production. Prog Lipid Res 49: 235-249. 
Benzioni A, Van Boven M, Ramamoorthy S, Mills D. 2007. Dynamics of fruit growth, accumulation of wax esters, simmondsins, proteins and carbohydrates in jojoba. Indu Crop Prod 26: 337-344.

Bleckmann A, Alter S, Dresselhaus T. 2014. The beginning of a seed: Regulatory mechanisms of double fertilization. Front Plant Sci 5: 452.

Bonaventure G, Salas JJ, Pollard MR, Ohlrogge JB. 2003. Disruption of the FATB gene in Arabidopsis demonstrates an essential role of saturated fatty acids in plant growth. Plant Cell 15: 1020-1033.

Boulard C, Fatihi A, Lepiniec L, Dubreucq B. 2017. Regulation and evolution of the interaction of the seed B3 transcription factors with NF-Y subunits. Biochim Biophys Acta Gene Regul Mech 1860: 1069-1078.

Brown AP, Johnson P, Rawsthorne S, Hills MJ. 1998. Expression and properties of acyl-CoA binding protein from Brassica napus. Plant Physiol Biochem 36: 629-635.

Burgal J, Shockey J, Lu C, et al. 2008. Metabolic engineering of hydroxy fatty acid production in plants: RcDGAT2 drives dramatic increases in ricinoleate levels in seed oil. Plant Biotechnol J 6: 819-831.

Cai G, Wang G, Kim S-C, Li J, Zhou Y, Wang X. 2021. Increased expression of fatty acid and $\mathrm{ABC}$ transporters enhances seed oil production in camelina. Biotechnol Biofuels 14: 49.

Cai Y, Goodman JM, Pyc M, Mullen RT, Dyer JM, Chapman KD. 2015. Arabidopsis SEIPIN proteins modulate triacylglycerol accumulation and influence lipid droplet proliferation. Plant Cell 27: 2616-2636.

Cai Y, McClinchie E, Price A, et al. 2017. Mouse fat storage-inducing transmembrane protein 2 (FIT2) promotes lipid droplet accumulation in plants. Plant Biotechnol J 15: 824-836.

Cernac A, Benning C. 2004. WRINKLED1 encodes an AP2/EREB domain protein involved in the control of storage compound biosynthesis in Arabidopsis. Plant J 40: 575-585.

Ciurescu G, Ropota M, Toncea I, Habeanu M. 2016. Camelia (Camelina sativa L. Crantz Variety) oil and seeds as n-3 fatty acids rich products in broiler diets and its effects on performance, meat fatty acid composition, immune tissue weights, and plasma metabolic profile. J Agric Sci Technol 18: 315-326.

Chapman KD, Ohlrogge JB. 2012. Compartmentation of triacylglycerol accumulation in plants. J Biol Chem 287: 2288-2294.

Chen M, Xuan L, Wang Z, et al. 2014. TRANSPARENT TESTA8 inhibits seed fatty acid accumulation by targeting several seed development regulators in Arabidopsis. Plant Physiol 165: 905-916.

Chen M, Zhang B, Li C, Kulaveerasingam H, Chew FT, Yu H. 2015. TRANSPARENT TESTA GLABRA1 regulates the accumulation of seed storage reserves in Arabidopsis. Plant Physiol 169: 391402.

Clemente TE, Cahoon EB. 2009. Soybean oil: Genetic approaches for modification of functionality and total content. Plant Physiol 151: 1030-1040.

d'Andréa S, Canonge M, Beopoulos A, et al. 2007. At5g50600 encodes a member of the short-chain dehydrogenase reductase superfamily with 11 beta- and 17 beta-hydroxysteroid dehydrogenase activities associated with Arabidopsis thaliana seed oil bodies. Biochimie 89: 222-229.

Dahlqvist A, Stahl U, Lenman M, et al. 2000. Phospholipid: diacylglycerol acyltransferase: an enzyme that catalyzes the acylCoA-independent formation of triacylglycerol in yeast and plants. Proc Natl Acad Sci USA 97: 6487-6492.

Dar AA, Choudhury AR, Kancharla PK, Arumugam N. 2017. The FAD2 gene in plants: occurrence, regulation, and role. Front Plant Sci 8: 1789.
Demski K, Jeppson S, Lager I, et al. 2019. Isoforms of acyl-CoA: Diacylglycerol acyltransferase2 differ substantially in their specificities toward erucic acid. Plant Physiol 181: 1468-1479.

Ding LN, Gu SL, Zhu FG, et al. 2020. Long-chain acyl-CoA synthetase 2 is involved in seed oil production in Brassica napus. BMC Plant Biol 20: 21.

Do PT, Nguyen CX, Bui HT, et al. 2019. Demonstration of highly efficient dual gRNA CRISPR/cas9 editing of the homeologous GMFAD2-1A and GMFAD2-1B genes to yield a high oleic, low linoleic and $\alpha$-linolenic acid phenotype in soybean. BMC Plant Biol 19: 311.

Dresselhaus T, Sprunck S, Wessel GM. 2016. Fertilization mechanisms in flowering plants. Curr Biol 26: R125-R139. https://doi. org/10.1016/j.cub.2015.12.032.

Du C, Chen Y, Wang K, et al. 2018. Strong co-suppression impedes an increase in polyunsaturated fatty acids in seeds overexpressing FAD2. J Exp Bot 70: 985-994.

Durrett TP, Benning C, Ohlrogge J. 2008. Plant triacylglycerols as feedstocks for the production of biofuels. Plant J 54: 593-607.

Dyer JM, Stymne S, Green AG, Carlsson AS. 2008. High-value oils from plants. Plant J 54: 640-655.

Engeseth NJ, Pacovsky RS, Newman T, Ohlrogge JB. 1996. Characterization of an acyl-CoA-binding protein from Arabidopsis thaliana. Arch Biochem Biophys 331: 55-62.

Focks N, Benning C. 1998. WRINKLED1: A novel, low-seed-oil mutant of Arabidopsis with a deficiency in the seed-specific regulation of carbohydrate metabolism. Plant Physiol 118: 91101.

Froissard M, D'Andréa S, Boulard C, Chardot T. 2009. Heterologous expression of AtClo1, a plant oil body protein, induces lipid accumulation in yeast. FEMS Yeast Res 9: 428-438.

Gao H, Gao Y, Zhang F, et al. 2021. Functional characterization of an novel acyl-CoA: Diacylglycerol acyltransferase 3-3 (CsDGAT3-3) gene from Camelina sativa. Plant Sci 303: 110752.

Gonzalez-Solis A, Han G, Gan L, et al. 2020. Unregulated sphingolipid biosynthesis in gene-edited Arabidopsis ORM mutants results in nonviable seeds with strongly reduced oil content. Plant Cell 32: 2474-2490.

Greer MS, Cai Y, Gidda SK, et al. 2020. SEIPIN isoforms interact with the membrane-tethering protein VAP27-1 for lipid droplet formation. Plant Cell 32: 2932-2950.

Hanano A, Burcklen M, Flenet M, et al. 2006. Plant seed peroxygenase is an original heme-oxygenase with an EF-hand calcium binding motif. J Biol Chem 281: 33140-33151.

Harker M, Hellyer A, Clayton JC, Duvoix A, Lanot A, Safford R. 2003. Co-ordinate regulation of sterol biosynthesis enzyme activity during accumulation of sterols in developing rape and tobacco seed. Planta 216: 707-715.

He M, Qin CX, Wang X, Ding NZ. 2020. Plant unsaturated fatty acids: Biosynthesis and regulation. Front Plant Sci 11: 390.

Hernández ML, Whitehead L, He Z, et al. 2012. A cytosolic acyltransferase contributes to triacylglycerol synthesis in sucroserescued Arabidopsis seed oil catabolism mutants. Plant Physiol 160: 215-225.

Hills MJ, Dann R, Lydiate D, Sharpe A. 1994. Molecular cloning of a cDNA from Brassica napus L. for a homologue of acyl-CoAbinding protein. Plant Mol Biol 25: 917-920.

Hsiao AS, Haslam RP, Michaelson LV, et al. 2014. Arabidopsis cytosolic acyl-CoA-binding proteins ACBP4, ACBP5 and ACBP6 have overlapping but distinct roles in seed development. Biosci Rep 34: e00165.

Huang AHC. 2018. Plant lipid droplets and their associated proteins: potential for rapid advances. Plant Physiol 176: 1894-1918. 
Ischebeck T, Krawczyk HE, Mullen RT, Dyer JM, Chapman KD. 2020. Lipid droplets in plants and algae: distribution, formation, turnover and function. Semin Cell Dev Biol 108: 82-93.

Ivarson E, Iven T, Sturtevant D, et al. 2017. Production of wax esters in the wild oil species Lepidium campestre. In Crops Prod 108: 535-542.

Iven T, Hornung E, Heilmann M, Feussner I. 2016. Synthesis of oleyl oleate wax esters in Arabidopsis thaliana and Camelina sativa seed oil. Plant Biotechnol J 14: 252-259.

Jacquier N, Mishra S, Choudhary V, Schneiter R. 2013. Expression of oleosin and perilipins in yeast promotes formation of lipid droplets from the endoplasmic reticulum. J Cell Sci 126: 51985209 .

Jako C, Kumar A, Wei Y, et al. 2001. Seed-specific over-expression of an Arabidopsis cDNA encoding a diacylglycerol acyltransferase enhances seed oil content and seed weight. Plant Physiol 126: 861-874.

Jessen D, Roth C, Wiermer M, Fulda M. 2015. Two activities of longchain acyl-coenzyme A synthetase are involved in lipid trafficking between the endoplasmic reticulum and the plastid in Arabidopsis. Plant Physiol 167: 351-366.

Kachroo A, Shanklin J, Whittle E, Lapchyk L, Hildebrand D, Kachroo P. 2007. The Arabidopsis stearoyl-acyl carrier protein-desaturase family and the contribution of leaf isoforms to oleic acid synthesis. Plant Mol Biol 63: 257-271.

Kalscheuer R, Stöveken T, Luftmann H, Malkus U, Reichelt R, Steinbüchel A. 2006. Neutral lipid biosynthesis in engineered Escherichia coli: Jojoba oil-like wax esters and fatty acid butyl esters. Appl Environ Microbiol 72: 1373-1379.

Kanai M, Yamada T, Hayashi M, Mano S, Nishimura M. 2019. Soybean (Glycine max L.) triacylglycerol lipase GmSDP1 regulates the quality and quantity of seed oil. Sci Rep 9: 8924.

Katavic V, Reed DW, Taylor DC, et al. 1995. Alteration of seed fatty acid composition by an ethyl methanesulfonate-induced mutation in Arabidopsis thaliana affecting diacylglycerol acyltransferase activity. Plant Physiol 108: 399-409.

Kazaz S, Barthole G, Domergue F, et al. 2020. Differential activation of partially redundant $\Delta 9$ stearoyl-ACP desaturase genes is critical for omega-9 monounsaturated fatty acid biosynthesis during seed development in Arabidopsis. Plant Cell 32: 36133637.

Kelly AA. 2018. Lipid composition of Arabidopsis thaliana seeds. In: Wenk M, ed. Encyclopedia of lipidomics. Dordrecht: Springer.

Kim HU, Hsieh K, Ratnayake C, Huang AH. 2002. A novel group of oleosins is present inside the pollen of Arabidopsis. $J$ Biol Chem 277: 22677-22684.

Kim HU, Lee KR, Go YS, Jung JH, Suh MC, Kim JB. 2011. Endoplasmic reticulum-located PDAT1-2 from castor bean enhances hydroxy fatty acid accumulation in transgenic plants. Plant Cell Physiol 52: 983-993.

Kim S, Yamaoka Y, Ono H, et al. 2013. AtABCA9 transporter supplies fatty acids for lipid synthesis to the endoplasmic reticulum. Proc Natl Acad Sci USA 110: 773-778.

Kong Q, Ma W. 2018. WRINKLED1 transcription factor: How much do we know about its regulatory mechanism? Plant Sci 272: 153156.

Kretzschmar FK, Doner NM, Krawczyk HE, et al. 2020. Identification of low-abundance lipid droplet proteins in seeds and seedlings. Plant Physiol 182: 1326-1345.

Lager I, Jeppson S, Gippert AL, Feussner I, Stymne S, Marmon S. 2020. Acyltransferases regulate oil quality in Camelina sativa through both acyl donor and acyl acceptor specificities. Front Plant Sci 11: 1144.
Lai SH, Chye ML. 2021. Plant acyl-CoA-binding proteins-their lipid and protein interactors in abiotic and biotic stresses. Cells 10(5): 1064.

Lardizabal K, Effertz R, Levering C, et al. 2008. Expression of Umbelopsis ramanniana DGAT2A in seed increases oil in soybean. Plant Physiol 148: 89-96.

Lardizabal KD, Metz JG, Sakamoto T, Hutton WC, Pollard MR, Lassner MW. 2000. Purification of a jojoba embryo wax synthase, cloning of its cDNA, and production of high levels of wax in seeds of transgenic Arabidopsis. Plant Physiol 122: 645-655.

Lee HG, Kim H, Suh MC, Kim HU, Seo PJ. 2018. The MYB96 transcription factor regulates triacylglycerol accumulation by activating DGAT1 and PDAT1 expression in Arabidopsis seeds. Plant Cell Physiol 59: 1432-1442.

Lee KR, Jeon I, Yu H, et al. 2021. Increasing monounsaturated fatty acid contents in hexaploid Camelina sativa seed oil by FAD2 gene knockout using CRISPR-Cas9. Front Plant Sci 12: 702.

Li Y, Beisson F, Pollard M, Ohlrogge J. 2006. Oil content of Arabidopsis seeds the influence of seed anatomy, light and plantto-plant variation. Phytochemistry 67: 904-15.

Li R, Yu K, Hildebrand DF. 2010. DGAT1, DGAT2 and PDAT expression in seeds and other tissues of epoxy and hydroxy fatty acid accumulating plants. Lipids 45: 145-157.

Li N, Gügel IL, Giavalisco P, et al. 2015. FAX1, a novel membrane protein mediating plastid fatty acid export. PLoS Biol 13: e1002053.

Li N, Xu C, Li-Beisson Y, Philippar K. 2016. Fatty acid and lipid transport in plant cells. Trends Plant Sci 21: 145-158.

Li D, Jin C, Duan S, et al. 2017. MYB89 transcription factor represses seed oil accumulation. Plant Physiol 173: 1211-1225.

Li X, Guan R, Fan J, Zhu LH. 2019. Development of industrial oil crop Crambe abyssinica for wax ester production through metabolic engineering and cross breeding. Plant Cell Physiol 60: 1274-1283.

Li N, Meng H, Li S, et al. 2020. Two plastid fatty acid exporters contribute to seed oil accumulation in Arabidopsis. Plant Physiol 182: 1910-1919.

Lin LJ, Tzen JT. 2004. Two distinct steroleosins are present in seed oil bodies. Plant Physiol Biochem 42: 601-608.

Liu J, Hua W, Zhan G, et al. 2010. Increasing seed mass and oil content in transgenic Arabidopsis by the overexpression of WRI1like gene from Brassica napus. Plant Physiol Biochem 48: 9-15.

Liu WX, Liu HL, Qu le Q. 2013. Embryo-specific expression of soybean oleosin altered oil body morphogenesis and increased lipid content in transgenic rice seeds. Theor Appl Genet 126: 2289-2297.

Lou Y, Schwender J, Shanklin J. 2014. FAD2 and FAD3 desaturases form heterodimers that facilitate metabolic channeling in vivo. J Biol Chem 289: 17996-18007.

López-Ribera I, La Paz JL, Repiso C, et al. 2014. The evolutionary conserved oil body associated protein OBAP1 participates in the regulation of oil body size. Plant Physiol 164: 1237-1249.

Lu C, Xin Z, Ren Z, Miquel M, Browse J. 2009. An enzyme regulating triacylglycerol composition is encoded by the ROD1 gene of Arabidopsis. Proc Natl Acad Sci USA 106: 18837-18842.

Lu S, Aziz M, Sturtevant D, Chapman KD, Guo L. 2020. Heterogeneous Distribution of Erucic Acid in Brassica napus Seeds. Front. Plant Sci. 10: 1744.

Lung SC, Weselake RJ. 2006. Diacylglycerol acyltransferase: A key mediator of plant triacylglycerol synthesis. Lipids 41: 1073-1088.

Lung SC, Chye ML. 2016. Deciphering the roles of acyl-CoA-binding proteins in plant cells. Protoplasma 253: 1177-1195. 
Ma S, Du C, Taylor DC, Zhang M. 2021. Concerted increases of FAE1 expression level and substrate availability improve and singularize the production of very-long-chain fatty acids in Arabidopsis seeds. Plant Direct 5: e00331.

Marmon S, Sturtevant D, Herrfurth C, Chapman K, Stymne S, Feussner I. 2017. Two acyltransferases contribute differently to linolenic acid levels in seed oil. Plant Physiol 173: 2081-2095.

Matthaus B, Özcan MM, Al Juhaimi F. 2016. Some rape/canola seed oils: Fatty acid composition and tocopherols. Z Naturforsch $C J$ Biosci 71: 73-77.

Metz JG, Pollard MR, Anderson L, Hayes TR, Lassner MW. 2000. Purification of a jojoba embryo fatty acyl-coenzyme A reductase and expression of its cDNA in high erucic acid rapeseed. Plant Physiol 122: 635-644.

Mhaske V, Beldjilali K, Ohlrogge J, Pollard M. 2005. Isolation and characterization of an Arabidopsis thaliana knockout line for phospholipid: Diacylglycerol transacylase gene (At5g13640). Plant Physiol Biochem 43: 413-417.

Michaelson LV, Napier JA, Molino D, Faure JD. 2016. Plant sphingolipids: Their importance in cellular organization and adaption. Biochim Biophys Acta 1861: 1329-1335.

Mietkiewska E, Brost JM, Giblin EM, Barton DL, Taylor DC. 2007. Cloning and functional characterization of the fatty acid elongase 1 (FAE1) gene from high erucic Crambe abyssinica cv. Prophet. Plant Biotechnol J 5: 636-645.

Miquel M, Trigui G, d'Andréa S, et al. 2014. Specialization of oleosins in oil body dynamics during seed development in Arabidopsis seeds. Plant Physiol 164: 1866-1878.

Miwa TK. 1971. Jojoba oil wax esters and derived fatty acids and alcohols: Gas chromatographic analyses. J Am Oil Chem Soc 48: 259-264.

Mu J, Tan H, Zheng Q, et al. 2008. LEAFY COTYLEDON1 is a key regulator of fatty acid biosynthesis in Arabidopsis. Plant Physiol 148: 1042-1054.

Naested H, Frandsen GI, Jauh GY, et al. 2000. Caleosins: Ca2+binding proteins associated with lipid bodies. Plant Mol Biol 44: 463-476.

Oakes J, Brackenridge D, Colletti R, et al. 2011. Expression of fungal diacylglycerol acyltransferase2 genes to increase kernel oil in maize. Plant Physiol 155: 1146-1157.

Ohlrogge J, Browse J. 1995. Lipid biosynthesis. Plant Cell 7: 957970.

Ohlrogge JB, Pollard MR, Stumpf PK. 1978. Studies on biosynthesis of waxes by developing jojoba seed tissue. Lipids 13: 203-210.

Ozseyhan ME, Li P, Na G, Li Z, Wang C, Lu C. 2018. Improved fatty acid profiles in seeds of Camelina sativa by artificial microRNA mediated FATB gene suppression. Biochem Biophys Res Commun 503: 621-624.

Poxleitner M, Rogers SW, Lacey Samuels A, Browse J, Rogers JC. 2006. A role for caleosin in degradation of oil-body storage lipid during seed germination. Plant $J$ 47: 917-933.

Premnath A, Narayana M, Ramakrishnan C, Kuppusamy S, Chockalingam V. 2016. Mapping quantitative trait loci controlling oil content, oleic acid and linoleic acid content in sunflower (Helianthus annuus L.). Mol Breed 36: 106.

Purkrtova Z, d'Andrea S, Jolivet P, et al. 2007. Structural properties of caleosin: a MS and CD study. Arch Biochem Biophys 464: 335343.

Pyc M, Cai Y, Gidda SK, et al. 2017. Arabidopsis lipid dropletassociated protein (LDAP) - Interacting protein (LDIP) influences lipid droplet size and neutral lipid homeostasis in both leaves and seeds. Plant J 92: 1182-1201.
Pyc M, Gidda SK, Seay D, et al. 2021. LDIP cooperates with SEIPIN and LDAP to facilitate lipid droplet biogenesis in Arabidopsis. Plant Cell 33: 3076-3103.

Raboanatahiry NH, Lu G, Li M. 2015a. Computational prediction of acyl-CoA binding proteins structure in Brassica napus. PLoS One 10: e0129650.

Raboanatahiry NH, Yin Y, Chen L, Li M. 2015b. Genome-wide identification and phylogenic analysis of kelch motif containing ACBP in Brassica napus. BMC Genomics 16: 512.

Raboanatahiry N, Wang B, Yu L, Li M. 2018. Functional and structural diversity of acyl-CoA binding proteins in oil crops. Front Genet 9: 182.

Rajangam AS, Gidda SK, Craddock C, Mullen RT, Dyer JM, Eastmond PJ. 2013. Molecular characterization of the fatty alcohol oxidation pathway for wax-ester mobilization in germinated jojoba seeds. Plant Physiol 161: 72-80.

Regmi A, Shockey J, Kotapati HK, Bates PD. 2020. Oil-producing metabolons containing DGAT1 use separate substrate pools from those containing DGAT2 or PDAT. Plant Physiol 184: 720-737.

Roesler K, Shen B, Bermudez E, et al. 2016. An improved variant of soybean type 1 diacylglycerol acyltransferase increases the oil content and decreases the soluble carbohydrate content of soybeans. Plant Physiol 171: 878-893.

Rost TL, Paterson KE. 1978. Structural and histochemical characterization of the cotyledon storage organelles of jojoba (Simmondsia chinensis). Protoplasma 95: 1-10.

Routaboul JM, Benning C, Bechtold N, Caboche M, Lepiniec L. 1999. The TAG1 locus of Arabidopsis encodes for a diacylglycerol acyltransferase. Plant Physiol Biochem 37: 831-840.

Saha S, Enugutti B, Rajakumari S, Rajasekharan R. 2006. Cytosolic triacylglycerol biosynthetic pathway in oilseeds. Molecular cloning and expression of peanut cytosolic diacylglycerol acyltransferase. Plant Physiol 141: 1533-1543.

Salas JJ, Ohlrogge JB. 2002. Characterization of substrate specificity of plant FATA and FATB acyl-ACP thioesterases. Arch Biochem Biophys 403: 25-34.

Shao Q, Liu X, Su T, Ma C, Wang P. 2019. New insights into the role of seed oil body proteins in metabolism and plant development. Front Plant Sci 10: 1568.

Shockey JM, Gidda SK, Chapital DC, et al. 2006. Tung tree DGAT1 and DGAT2 have nonredundant functions in triacylglycerol biosynthesis and are localized to different subdomains of the endoplasmic reticulum. Plant Cell 18: 2294-2313.

Siloto RM, Findlay K, Lopez-Villalobos A, Yeung EC, Nykiforuk CL, Moloney MM. 2006. The accumulation of oleosins determines the size of seed oil bodies in Arabidopsis. Plant Cell 18: 1961-1974.

Sturtevant D, Lu S, Zhou ZW, et al. 2020. The genome of jojoba (Simmondsia chinensis): a taxonomically isolated species that directs wax ester accumulation in its seeds. Sci $A d v$ 6: eaay 3240.

Taurino M, Costantini S, De Domenico S, et al. 2018. SEIPIN proteins mediate lipid droplet biogenesis to promote pollen transmission and reduce seed dormancy. Plant Physiol 176: 1531-1546.

Taylor DC, Zhang Y, Kumar A, et al. 2009. Molecular modification of triacylglycerol accumulation by over-expression of DGAT1 to produce canola with increased seed oil content under field conditions. Botany 87: 533-543.

Tellier F, Maia-Grondard A, Schmitz-Afonso I, Faure JD. 2014. Comparative plant sphingolipidomic reveals specific lipids in seeds and oil. Phytochemistry 103: 50-58.

Tian R, Wang F, Zheng Q, Niza VMAGE, Downie AB, Perry SE. 2020. Direct and indirect targets of the Arabidopsis seed 
transcription factor ABSCISIC ACID INSENSITIVE3. Plant $J$ 103: 1679-1694.

Troncoso-Ponce MA, Barthole G, Tremblais G, et al. 2016a. Transcriptional activation of two delta-9 palmitoyl-ACP desaturase genes by MYB115 and MYB118 is critical for biosynthesis of omega-7 monounsaturated fatty acids in the endosperm of Arabidopsis seeds. Plant Cell 28: 2666-2682.

Troncoso-Ponce MA, Nikovics K, Marchive C, Lepiniec L, Baud S. 2016b. New insights on the organization and regulation of the fatty acid biosynthetic network in the model higher plant Arabidopsis thaliana. Biochimie 120: 3-8.

Turchetto-Zolet AC, Christoff AP, Kulcheski FR, Loss-Morais G, Margis R, Margis-Pinheiro M. 2016. Diversity and evolution of plant diacylglycerol acyltransferase (DGATS) unveiled by phylogenetic, gene structure and expression analyses. Genet Mol Biol 39: 524-538.

Valitova JN, Sulkarnayeva AG, Minibayeva FV. 2016. Plant sterols: Diversity, biosynthesis, and physiological functions. Biochemistry (Mosc) 81: 819-834.

van Erp H, Bates PD, Burgal J, Shockey J, Browse J. 2011. Castor phospholipid: Diacylglycerol acyltransferase facilitates efficient metabolism of hydroxy fatty acids in transgenic Arabidopsis. Plant Physiol 155: 683-693.

Voelker T, Kinney AJ. 2001. Variations in the biosynthesis of seedstorage lipids. Annu Rev Plant Physiol Plant Mol Biol 52: 335361.

Vogel PA, Bayon de Noyer S, Park H, et al. 2019. Expression of the Arabidopsis WRINKLED 1 transcription factor leads to higher accumulation of palmitate in soybean seed. Plant Biotechnol J 17: 1369-1379.

Wang L, Wang T, Fehr WR. 2006. Effect of seed development stage on sphingolipid and phospholipid contents in soybean seeds. $J$ Agric Food Chem 54: 7812-7816.

Wenning L, Yu T, David F, Nielsen J, Siewers V. 2017. Establishing very long-chain fatty alcohol and wax ester biosynthesis in Saccharomyces cerevisiae. Biotechnol Bioeng 114: 1025-1035.

Wenning L, Ejsing CS, David F, Sprenger RR, Nielsen J, Siewers V. 2019. Increasing jojoba-like wax ester production in Saccharomyces cerevisiae by enhancing very long-chain, monounsaturated fatty acid synthesis. Microb Cell Fact 18: 49.

Weselake RJ, Shah S, Tang M, et al. 2008. Metabolic control analysis is helpful for informed genetic manipulation of oilseed rape (Brassica napus) to increase seed oil content. J Exp Bot 59: 35433549 .

Woodfield HK, Sturtevant D, Borisjuk L, et al. 2017. Spatial and temporal mapping of key lipid species in brassica napus seeds. Plant Physiol 173: 1998-2009.
Wu P, Xu X, Li J, et al. 2021. Seed-specific overexpression of cotton GhDGAT1 gene leads to increased oil accumulation in cottonseed. The Crop Journal 9: 487-490.

Xu X, Bittman R, Duportail G, Heissler D, Vilcheze C, London E. 2001. Effect of the structure of natural sterols and sphingolipids on the formation of ordered sphingolipid/sterol domains (rafts). Comparison of cholesterol to plant, fungal, and disease-associated sterols and comparison of sphingomyelin, cerebrosides, and ceramide. J Biol Chem 276: 33540-33546.

$\mathrm{Xu}$ Y, Caldo KMP, Pal-Nath D, et al. 2018. Properties and biotechnological applications of acyl-CoA: Diacylglycerol acyltransferase and phospholipid: Diacylglycerol acyltransferase from terrestrial plants and microalgae. Lipids 53: 663-688.

Yu D, Hornung E, Iven T, Feussner I. 2018. High-level accumulation of oleyl oleate in plant seed oil by abundant supply of oleic acid substrates to efficient wax ester synthesis enzymes. Biotechnol Biofuels 11: 53.

Yu L, Fan J, Zhou C, Xu C. 2021. Sterols are required for the coordinated assembly of lipid droplets in developing seeds. Nat Commun 12: 5598.

Zhang M, Fan J, Taylor DC, Ohlrogge JB. 2009. DGAT1 and PDAT1 acyltransferases have overlapping functions in Arabidopsis triacylglycerol biosynthesis and are essential for normal pollen and seed development. Plant Cell 21: 3885-3901.

Zhang TT, He H, Xu CJ, et al. 2021. Overexpression of type 1 and 2 diacylglycerol acyltransferase genes (JcDGAT1 and JcDGAT2) enhances oil production in the woody perennial biofuel plant Jatropha curcas. Plants (Basel) 10: 69

Zhao L, Katavic V, Li F, Haughn GW, Kunst L. 2010. Insertional mutant analysis reveals that long-chain acyl-CoA synthetase 1 (LACS1), but not LACS8, functionally overlaps with LACS9 in Arabidopsis seed oil biosynthesis. Plant J 64: 1048-1058.

Zhu LH, Krens F, Smith MA, et al. 2016. Dedicated industrial oilseed crops as metabolic engineering platforms for sustainable industrial feedstock production. Sci Rep 6: 22181.

Zienkiewicz K, Zienkiewicz A. 2020. Degradation of lipid droplets in plants and algae-right time, many paths, one goal. Front Plant Sci 11: 579019.

Zou J, Wei Y, Jako C, Kumar A, Selvaraj G, Taylor DC. 1999. The Arabidopsis thaliana tagl mutant has a mutation in a diacylglycerol acyltransferase gene. Plant J 19: 645-653.

Zulu NN, Popko J, Zienkiewicz K, Tarazona P, Herrfurth C, Feussner I. 2017. Heterologous co-expression of a yeast diacylglycerol acyltransferase (ScDGA1) and a plant oleosin (AtOLEO3) as an efficient tool for enhancing triacylglycerol accumulation in the marine diatom Phaeodactylum tricornutum. Biotechnol Biofuels 10: 187.

Cite this article as: Miklaszewska M, Zienkiewicz K, Inchana P, Zienkiewicz A. 2021. Lipid metabolism and accumulation in oilseed crops. OCL 28: 50 . 